\title{
A PESQUISA SOBRE JOGOS COMO RECURSOS DIDÁtICOS NO CAMPO DO ENSINO DE HISTÓRIA NO BRASIL: UM ESTUDO DO ESTADO DO CONHECIMENTO
}

The research on games as a didactic tool in the field of history teaching in Brazil: the state of art

\author{
Lucas Victor Silva ${ }^{1}$ \\ Marcello Paniz Giacomoni ${ }^{2}$ \\ Paulo Henrique Penna de Oliveira ${ }^{3}$ \\ Maurício Clipes Cunha ${ }^{4}$
}

\begin{abstract}
RESUMO: O objetivo deste artigo é abordar o desenvolvimento recente da pesquisa sobre jogos como recursos didáticos no campo do Ensino de História no Brasil. Para tanto, abordaremos a pertinência da reflexão sobre jogos no contexto da história escolar e, em seguida, esboçaremos o estado do conhecimento sobre a pesquisa sobre jogos de mesa e digitais no ensino da História. Por fim, este texto discutirá alguns caminhos teóricos construídos pelo campo, avanços conquistados e possíveis demandas para investigação futuras. Caraterizada pela diversidade teórica, a produção sobre a temática cresceu significativamente nos últimos 10 anos e privilegiou temas como a violência nos games, as aprendizagens promovidas pelos artefatos lúdicos e a criação e o uso de jogos de tabuleiro e digitais na história escolar.
\end{abstract}

Palavras-chave: Jogos. Games. Ensino de história. Historiografia

ABSTRACT: This article examines the recent development of researches on games as a didactic tool in the field of history teaching in Brazil. We support the relevance of scrutinizing the use of games in the historical context of Brazilian schools and the state of art on researching boardgames and digital games in the history of education. Finally, we highlight the theoretical paths built in the field, its recent breakthroughs and achievements, and some potential demands for future investigations. Characterized by theoretical diversity, the scientific production has grown significantly in the last 10 years. Themes such as violence, learning and the creation and use of games in history teaching were privileged.

Key-words: Boardgames. Digital games. History teaching. Historiography.

\footnotetext{
${ }^{1}$ Doutor em História pela Universidade Federal de Pernambuco. Professor da Universidade Federal Rural de Pernambuco. Contato: lucasvictor.ufrpe@gmail.com

${ }^{2}$ Doutor em Educação pela Universidade Federal do Rio Grande do Sul. Professor do Colégio de Aplicação da Universidade Federal do Rio Grande do Sul. Contato: marcello.giacomoni@gmail.com ${ }^{3}$ Mestre em Ensino de História pela Universidade Federal de Pernambuco (PROFHISTORIA). Professor da rede particular de Pernambuco. Contato: paulopenna_genos@yahoo.com.br

${ }^{4}$ Acadêmico do curso de Licenciatura em História da Universidade Federal do Rio Grande do Sul. Contato: mauricioclipes@gmail.com
} 


\section{Introdução}

Como qualquer área de conhecimento, o campo do Ensino de História deve ser pensado como resultado de procedimentos e práticas analíticas que devem ser seguidas para que o saber produzido seja reconhecido pelos pares (CERTEAU, 2002). Para tanto, existem diversas marcas textuais na escrita como a citação bibliográfica, que nos serve de ponte para uma comunidade de saber, sociabilidade e exercício de trabalho intelectual. O objetivo deste trabalho aqui apresentado é contribuir para o reconhecimento da existência de um círculo de investigação sobre jogos no ensino de História e apontar alguns dos limites e possibilidades dos que escreveram antes de nós. E, assim, reconhecer o avanço das discussões e a necessidade de trilhar novos caminhos. O diálogo escrito produz efeitos políticos no texto e no campo científico. Produz linhas de força e pontos de construção da legitimidade da pesquisa diante dos pares. Essas práticas científicas buscam atender aos critérios de confiabilidade, densidade, amadurecimento, aprofundamentos teóricos e conceituais e de conhecimento empírico sobre as fontes e resultados disponíveis (FERREIRA, 2002).

Neste texto, apresentamos um exercício do gênero discursivo "estado da arte" ou "estado do conhecimento" com o objetivo de contribuir para a abertura de questões de pesquisa sobre um objeto que tem recebido - apenas em tempos recentes - significativa atenção dos pesquisadores do Ensino de História no Brasil: os jogos como recursos didáticos para a história escolar (FERREIRA, 2002).

Este texto está organizado em três partes: primeiramente justificaremos a pertinência da reflexão sobre jogos no contexto da história escolar contemporânea; depois apresentaremos o estado do conhecimento sobre a pesquisa sobre jogos no ensino da História; e, por fim, sobre os caminhos teóricos que o campo tem construído sobre os fundamentos para o uso de jogos no ensino de História. 


\section{Por que precisamos jogar?}

O contexto de crise da História escolar torna urgente, dentre outros aspectos, a investigação sobre intervenções docentes inovadoras. A atualidade da história escolar está marcada por permanências que dificultam - quando não impossibilitam - a construção de aprendizagens significativas em sala de aula. Entretanto, neste panorama, há avanços importantes: a melhoria das coleções selecionadas e distribuídas para as escolas públicas pelo Programa Nacional do Livro Didático, o aumento da carga horária de estágio nos cursos de formação de professores e a criação de novas políticas públicas de formação inicial e continuada que aproximaram a universidade das escolas com o Programa Institucional de Bolsas de Iniciação à Docência (PIBID), O Programa Residência Pedagógica, a Rede Nacional do Mestrado Profissional em Ensino de História (PROFHISTORIA), o Programa Nacional de Formação de Professores da Educação Básica (PARFOR) e a Rede Nacional de Formação Continuada dos Profissionais do. Magistério da Educação Básica Pública (RENAFORM).

Há, ainda, grandes batalhas a serem travadas. Começamos pela luta para mudar a tibieza dos historiadores acadêmicos (representados na ANPUH-Brasil) em agir em defesa da educação básica e dos professores de História. Ressaltamos também os desafios decorrentes da implementação da Base Nacional Comum Curricular (BNCC) e da necessidade de reconstrução do lugar da história escolar no "Novo Ensino Médio". E o que dizer das ameaças do movimento Escola Sem Partido e do atual contexto político à liberdade de cátedra e à diversidade ideológica?

\footnotetext{
Torna-se urgente abrirmos espaço para abordagens escolares que [...] coloquem o ensino de História a serviço da vida e da construção da cidadania que deve proporcionar condições para que o futuro cidadão possa operar escolhas racionais no regime democrático e possa situar a si mesmo e os problemas sociais no tempo e no espaço (SILVA; SILVA, 2016, p. 482).
}

Está posto o desafio aos militantes da docência e da pesquisa deste campo, dada a importância política do ensino de História, da construção de novas práticas educativas que promovam além do pensamento crítico, a criatividade, a ludicidade, a sensibilidade, a crítica, a inovação e a produção de novas 
subjetividades. Para tanto, é preciso deslocar os processos educativos para além da fragmentação, da rotina, da repetição, da monotonia, da massificação. É preciso reinventar uma prática educativa que seja fundamentada na dúvida, ou seja, no questionamento das certezas, dogmas e do mundo que nos circunda (ALBUQUERQUE JUNIOR, 2019). Uma pedagogia outra que abra espaço para pensarmos o novo e que tenha como desafio vital o sonho, como movimento que nos transporta da prisão do presente e nos joga numa simpatia com o tempo real, a duração (BERGSON, 2010).

Um recurso didático ou perspectiva teórica inovadores não precisam ser tomados como redentores da educação. O uso de materiais lúdicos no ensino de História, em especial, deve ser encarado como uma possibilidade de renovação das atividades didáticas entre outras possíveis. É preciso também reconhecermos que para renovar a história escolar pouco adianta adotarmos materiais e práticas docentes renovados se não existem políticas públicas de formação continuada e de melhoria da carreira e das condições de trabalho. No entanto, isso não significa que a mudança nas práticas docentes e recursos didáticos seja dispensável em uma conjuntura política desfavorável à melhoria das condições de trabalho dos educadores através políticas públicas. A fragilidade da escola e do professor são funcionais para a continuidade da precariedade das condições de trabalho. Não é justamente esse o discurso de grupos políticos conservadores: a escola é ruim porque os professores são mal formados e não ensinam, doutrinam. O que fazer para melhorar a educação: criminalizar o trabalho docente, como propõem o movimento Escola Sem Partido e os apoiadores do atual governo? Precisamos insistir na legitimação da docência não mais como reprodutora, mas como atividade intelectual produtora de um tipo específico de conhecimento, o escolar. A multiplicidade dos saberes docentes justifica a necessidade de revalorização do trabalho escolar e de garantia da liberdade de cátedra. Desse modo, nos parece que, se por um lado estamos atentos aos movimentos do presente, que cerceiam e procuram coibir o pensamento; por outro lado, queremos reafirmar o caráter criativo e reflexivo da sala de aula de História.

\section{Jogos no ensino de História}


Diversos pesquisadores brasileiros acreditaram e acreditam na pertinência dos jogos como recursos didáticos para a história escolar. É sobre essa trajetória coletiva recente que iremos abordar a partir de agora, nesta segunda parte do texto.

No campo da pesquisa em educação no Brasil, a pesquisadora Tizuko Morchida Kishimoto (1995, 1996, 2009, 2016) foi pioneira na abordagem dos jogos como recursos pedagógicos, sobretudo quando pensamos na educação infantil e no ensino dos anos iniciais do ensino fundamental. A partir da década de 1990, estabeleceu-se um diálogo entre a pesquisa em educação no Brasil e pensadores que tematizam o jogo como prática cultural humana, tais como Huizinga (2014), Roger Caillois (2017) e com a obra de pesquisadores sobre as relações entre jogos e educação como Gilles Brougère (2003) e Jean Vial (2015).

A pesquisadora Tânia Ramos Fortuna (2003, 2011a, 2011b, 2012, 2013, 2017) também se destaca no campo ao investigar aspectos teóricos sobre jogos, brincadeiras, formação de professores, jogos na educação infantil e a relação entre jogos e educação no pensamento ocidental. Vale ressaltar que Fortuna coordena, desde 1999, o programa de extensão universitária "Quem quer brincar?", na Universidade Federal do Rio Grande do Sul que realiza atividades formativas sobre a prática de atividades lúdicas na Educação e que disponibiliza uma brinquedoteca para empréstimo de brinquedos e jogos. ${ }^{5}$

A produção sobre jogos, no âmbito do ensino de História, para os anos finais do ensino fundamental e para o ensino médio é recente na história do campo de ensino da História no país. Nosso levantamento bibliográfico buscou uma série de caminhos. Uma primeira tentativa deu-se através da pesquisa nas bases Scielo e Google Acadêmico com as seguintes palavras-chave: jogos, jogo, ensino de história e história. Não foram localizadas pesquisas que relacionassem os dois temas no Scielo. Já no Google Acadêmico, vários trabalhos foram localizados, em diferentes formatos de publicação, desde artigos científicos a teses e capítulos de livros. A produção concentra-se sobretudo em dissertações, com especial presença dos trabalhos produzidos no âmbito do Mestrado Profissional em Ensino de História, sendo ainda poucas as teses de doutorado. Em relação à divulgação

\footnotetext{
${ }^{5} \mathrm{O}$ sítio do referido programa está disponível no endereço https://www.ufrgs.br/quemquerbrincar/ (UFRGS, 2020).
} 
científica, nosso levantamento demonstrou uma concentração maior de publicações em capítulos de livros do que em artigos em revistas acadêmicas.

Os primeiros textos diagnosticavam a necessidade de atualizar a História escolar através do uso "linguagens alternativas" sendo o jogo uma possibilidade, procuravam fundamentos teóricos que justificavam o uso de jogos no Ensino de História, bem como traziam relatos de experiências de ensino com materiais lúdicos. É o caso do trabalho publicado na Revista História Hoje de autoria de Maria A. Belintane Fermiano (2005) intitulado O Jogo como um instrumento de trabalho no ensino de História? E do artigo O lúdico e o sério: experiências com jogos no ensino de história publicado na História \& Ensino, em 2007, de autoria de Débora El-Jaick Andrade (2007).

Em 2011, o historiador André P. Leme Lopes, em artigo de divulgação científica publicado na Revista de História da Biblioteca Nacional, defendia as possibilidades educativas dos jogos de tabuleiro e digitais para o ensino de conteúdos históricos. Ressaltava que tanto os games quanto os jogos "analógicos" se tornaram mais sofisticados deste a década de 1990. E seus usos pedagógicos teriam muitas vantagens em comparação com as abordagens tradicionais. Durante as sessões de jogos de temática histórica, cada vez mais praticadas pelos professores da educação básica, os alunos se motivam, se inquietam, se divertem e podem aprender com as experiências de desfechos alternativos da história jogada, ideias que ele vai desenvolver no texto Dados e cartas na escola: o potencial pedagógico dos jogos não-eletrônicos (LOPES; BERLIN, 2012). Para Lopes (2011, p. 77): "Essas competições, ainda por cima, podem ser repetidas com muito mais empenho e interesse do que uma leitura ou um filme, e fazem com que o aluno sinta a História como parte de sua vida". O pesquisador defende o uso dos jogos digitais comerciais e, no entanto, lamenta o pequeno número de criações relacionadas a história do Brasil que resume em duas: o Jogo da Cabanagem, desenvolvido em 2008 pelo Universidade Federal do Pará e Capoeira Legends, produzido em 2009, na Universidade de Southampton. No fim do artigo, profetiza: "o uso dessas "ferramentas pedagógicas" está apenas no início, mas vai muito além de um modismo" (LOPES, 2011, p. 79).

Na última década, pesquisadores e professores iniciaram um movimento de aproximação com os jogos. Muito recentemente, a utilização de jogos no ensino 
de História tem sido abordada como uma possibilidade de renovação das atividades didáticas. Em, Jogos e ensino de História, obra organizada pelos professores Marcello Paniz Giacomoni e Nilton Mullet Pereira (2013), pesquisadores e professores brasileiros tiveram acesso a reflexões de diversos pesquisadores do Rio Grande do Sul, como Fernando Seffner, Carla Meinerz e Tânia Fortuna, sobre aspectos teóricos e didáticos necessários referentes a esta temática: as relações entre brincar e aprender na tradição filosófica ocidental, possibilidades de aprendizagens significativas através do uso pedagógico dos jogos, tipos de jogos, exemplos de jogos de mesa e de seus usos na sala de aula, estratégias de avaliação das aprendizagens realizadas a partir de práticas docentes lúdicas, dentre outras temáticas. O livro também orienta sobre como docentes podem investir criatividade, inclusive na invenção de jogos de tabuleiro com temáticas históricas.

Os jogos digitais também se tornaram objetos de pesquisa no campo do Ensino de História. Destacamos os trabalhos da importante pesquisadora Lynn Alves que, dentre diversos aspectos do uso de games na educação básica, produziu trabalhos sobre violência, videogames e jogos eletrônicos no ensino de História. Com a tese de doutoramento Game over: jogos eletrônicos e violência, Lynn Alves (2005) faz uma discussão sobre os aspectos da violência contida nos games e em que medida isso seria um reflexo das relações sociais. O trabalho em questão ainda se propõe a discutir o conceito de violência, através de diversos campos do conhecimento, além de também fazer uma breve análise a respeito dos conteúdos trazidos nos principais jogos ditos como violentos. Essa discussão é importante principalmente devido à relação que se faz entre jogos com conteúdo violento e crescimento da violência entre os jovens. Na obra em questão, a autora chega à conclusão de que os jogos, apesar de poderem diminuir a sensibilidade das pessoas no tocante à violência, não estão relacionados aos comportamentos violentos de seus usuários, sendo eles uma forma de ressignificação do que lhes é apresentado pela vida em sociedade.

Dentre outros trabalhos de Alves, destacamos Os videogames como narrativas sobre o passado na pós-modernidade (ALVES; TELLES, 2017), Ficção e Narrativa: o lugar dos videogames no ensino de História (ALVES; TELLES, 2016b) e Ensino de história e videogame (ALVES; TELLES, 2016a), três artigos com co- 
autoria com Helyon Telles. Destacamos ainda o artigo Jogos, educação e história (ALVES, 2010) e duas obras de autoria coletiva: uma organizada por ela e Isa Coutinho intitulada Jogos digitais e aprendizagem: Fundamentos para uma prática baseada em evidências (ALVES; COUTINHO, 2016) e outra, mais recente, Museus virtuais e jogos digitais: novas linguagens para o estudo da história, organizada pela pesquisadora e por Alfredo Matta e Helyon Telles (ALVES, MATTA, TELLES, 2019). Além disso, coordena o projeto Comunidades Virtuais que disponibiliza jogos digitais produzidos sob sua orientação em site ${ }^{6}$.

Escolhendo um título sob a forma de uma pergunta, Jogos digitais e aprendizagens: o jogo Age of Empires III desenvolve idéias e raciocínios históricos de jovens jogadores?, o pesquisador Eucidio Pimenta Arruda (2009), mediante pesquisa de campo em sua tese de doutorado, abriu um verdadeiro campo de estudos no cenário do ensino de História no Brasil. Arruda (2009) problematiza a viabilidade do uso dos jogos eletrônicos com recurso utilizado na aprendizagem de conteúdos históricos, analisa as concepções de tempo e espaço presente em jogos eletrônicos e propõe uma classificação dos tipos de games existentes (jogos de ação, de estratégia em tempo real (RTS), esportes, simulação e RPG). O autor ressalta que as diferentes formas e estratégias dos jogos proporcionam experiências distintas e revelam espaço para diferentes formas de utilização. Arruda investigou como as habilidades e modos de pensar presentes durante as partidas de jogo digital permitem aprendizagens de formas de pensar e raciocinar historicamente, tais como imaginação, analogia e narração. Mesmo que o jogo não ensine a História escolar, o autor defende a criação de caminhos que possibilitem a mediação do professor com essas outras histórias extra-escolares, sobretudo as produzidas nos meios tecnológicos, já que a aprendizagem e o pertencimento no mundo digital são, do ponto de vista do autor, importantes para qualificar o ensino e as relações entre os jovens.

Na dissertação Games com narrativa histórica como dispositivo digital para mediação de experiências formativas em ensino de história: uma pesquisa com o

${ }^{6} \mathrm{O}$ site do Comunidades Virtuais pode ser acessado através do link: http://comunidadesvirtuais.pro.br/cv/. Outra iniciativa que visa divulgar os games como recursos para o ensino da História é o site Jogos digitais para ensinar história que funciona como guia didático digital, espaço de interação on-line e blog com materiais de apoio (https://www.jogosdehistoria.net/blog ) 
jogo "Game of Thrones" - RPG, Tárcio Roberto Macedo (2013) também desenvolve pesquisa de campo com os estudantes a partir da criação de grupo focal para analisar as percepções desses alunos enquanto jogam e como estes relacionam os aspectos apresentados no game aos conhecimentos já adquiridos sobre a cultura medieval.

A dissertação de autoria de Bergston Luan Santos (2014), Interpretando "Mundos": Jogos digitais e aprendizagem histórica, discute o ensino da história da independência das treze colônias norte-americanas a partir do jogo Assassin's Creed 3 e analisa as diferentes percepções dos jogadores a respeito do universo histórico criado no jogo.

O historiador Alex Alvarez Silva (2016, 2017a, 2017b, 2018, 2019) é outro pesquisador que tem investigado que tipo de aprendizagem histórica pode ser mobilizada nos jogos eletrônicos de simulações históricas e sobre as concepções de tempo histórico presentes nestes artefatos digitais. O autor defende a ideia de que existe uma lacuna de ordem teórico-metodológica no que se refere à relação entre o ensino de história e os conceitos e elementos historiográficos presentes nos games. A importância de buscarmos uma interação entre o ensino de história e os games estaria no fato de que, segundo Silva (2017a, 2017b), mesmo que seu objetivo primordial seja o entretenimento, e não propriamente a formação histórica, essas produções estariam se apropriando da cultura histórica contemporânea e guardando alguma relação com o conhecimento histórico. Sendo assim, umas das formas encontradas por Silva (2017a, 2017b) é pensar as avaliações a partir dos chamados princípios reguladores do game, ou seja, o tipo de interação que esses jogos permitem a seus usuários, além das interpretações realizadas por parte do jogador.

Uma das últimas produções analisadas para este trabalho, diz respeito à dissertação de José Anderson da Costa Gomes, defendida em 2019 e que carrega o título de Jogos digitais no ensino de história: uma análise do jogo Tríade Liberdade, Igualdade e Fraternidade. A dissertação analisa um game educativo disponibilizado pelo portal Comunidades Virtuais. O trabalho em questão ressalta a importância dos recursos digitais na atual sociedade além de discutir o processo de gamificação na educação, levando em conta seus aspectos positivos e 
negativos. A partir disso, o autor realiza uma análise a respeito dos aspectos técnicos e pedagógicos do game.

Outra abordagem é a esboçada na obra Ensino de História e games, através da qual a historiadora Marcella Costa (2017) nos convida a refletir sobre sua prática de ensino que adapta a metodologia da construção de jogos digitais para fins didáticos. A autora realiza discussão sobre as possibilidades práticas do uso da linguagem dos games no ambiente escolar com a promoção das aprendizagens por meio de projetos onde são criadas condições para que os próprios alunos, a partir dos conhecimentos desenvolvidos nas aulas de Roma Antiga, desenvolvam um roteiro para um game ambientado nesta época. O referido trabalho carrega o mérito de exemplificar como um professor pode encontrar meios de se aproximar da linguagem dos games sem ter necessariamente que dispor de uma estrutura repleta de computadores ou dispositivos para reproduzir tais jogos.

Outra dissertação a respeito dos games e conhecimento histórico é a de Khauan Pessanha Soares, defendida em 2018, intitulada Jovens e games: $A$ construção do conhecimento em história no ensino fundamental II com os jogos "Call of Duty". A investigação realizou uma pesquisa de campo na qual jovens compartilharam suas percepções sobre conteúdos históricos presentes no jogo comercial Call of Duty: World of war. O game também foi analisado em seus vários aspectos, suas narrativas, seus conteúdos históricos, seus elementos gráficos e suas possibilidades educativas.

Encontramos também trabalhos que defendem a pertinência educativa dos jogos de tabuleiro e analisam as possibilidades pedagógicas de jogos disponíveis no mercado Geek e sistemas de RPG. É o caso de publicação de Lucas Victor Silva em co-autoria com Cláudio Rodrigo Vasconcelos Silva (2016) sobre os jogos Timeline e Quissama. Também há trabalhos que relatam o processo de construção de jogos com fins didáticos e suas possibilidades. É o caso dos trabalhos de: Marcello Paniz Giacomoni (2013) sobre o jogo O Centralizador; da equipe ligada ao Laboratório de Ensino de História e Educação da UFRGS, com o jogo As Viagens do Tambor (PEREIRA, et. al., 2019); Lucas Victor Silva, Karla Ferreira e Camila Silva sobre a produção do jogo Você conhece: Mulheres do Brasil (2017) e Lucas Victor Silva sobre a construção do jogo Terras do Sol: entre tambores e lanças (2017). 
Um possível caminho a ser abordado e ainda pouco explorado seria a avaliação de práticas docentes da escola básica com o objetivo de confrontar as perspectivas teóricas e metodologias de ensino propostas com o chão da escola. Nesta perspectiva temos a dissertação de mestrado de Cláudio Rodrigo Vasconcelos Silva (2016) sobre a prática de professor de História que fez uso do role-playing game na sala de aula da rede pública de Pernambuco. A investigação concluiu que o uso do jogo na história escolar é capaz de produzir uma nova relação entre professor e alunos e entre estes e o conhecimento histórico escolar na medida em que: os estudantes são motivados a autonomamente produzir o conhecimento histórico no contexto dos aspectos cooperativos e competitivos do projeto didático lúdico; e há a oportunidade para a construção do estudante/jogador enquanto sujeito ético que fala, escuta, obtém respeito sobre suas opiniões e respeita as opiniões dos colegas.

A produção sobre a temática avançou especialmente no âmbito da produção científica da rede PROFHISTORIA com a elaboração de jogos como produto didático. Foram localizadas, ao todo, 17 dissertações no programa espalhadas em 12 instituições. São elas: UFPE, UFSC, UFRGS, UFRJ, UFF, UNESPAR, UDESC, PUCRIO, UEMS, UFSM, UCS e UNEB. Registraram duas dissertações: UFPE, UFRGS, UFRJ, UDESC e UFSM. As demais instituições registraram uma produção até novembro de 2019. Dessas 17 dissertações, 7 foram defendidas em 2016, 3 em 2017 e 7 em 2018. Tal produção, em um curto e recente espaço de tempo, revela a dinamicidade do desejo de uso de jogos pelos professores de História. Ainda mais quando comparamos com as demais dissertações encontradas, que somam apenas 7, entre 2008 e 2016, em Programas de Pós-Graduação de História Social, Educação e Tecnologia.

A experiência de temas e propostas foi variada: Tatiane de Souza Ritter (2016) elaborou jogo de tabuleiro para o ensino de História Agrária em uma escola do campo, justificando a necessidade de fugir das aulas tradicionais e levar o lúdico para a sala de aula; Marcia de Sousa da Silva Maia (2016) construiu um jogo informativo para o ensino de História dos povos indígenas, pensado de forma nãolinear, estimulando empatia e protagonismo indígena; Bruno Ornelas da Cunha (2016) que fez um jogo de cartas para ensinar história local, com protagonismo dos estudantes na construção do jogo; Carlos Eduardo da Souza Costa (2016) 
dissertou sobre o jogo de RPG como ferramenta para o desenvolvimento de narrativas e a temporalidade histórica; na dissertação de Lucas Roberto Soares Lopes (2016) foi abordado o processo protagonizado por docente e discentes do desenvolvimento do jogo digital de temática histórica Os revoltosos, justificando a utilização da tecnologia digital, em parte, para se opor à noção de "atraso" e "inutilidade" da História para com as demais ciências que produzem produtos tangíveis.

Há também o trabalho que analisou as potencialidades educativas de jogos digitais comerciais como recursos didáticos da história escolar. É o caso de Artur Duarte Peixoto (2016), que analisou dois jogos (um com fins didáticos e outro comercial) que retratavam a Revolução Francesa, concluindo que o jogo é uma ferramenta do professor, que é quem realmente ensina história. O trabalho em questão nos permite refletir sobre diversas temáticas além das possibilidades pedagógicas dos jogos Assassin's Creed Unity e Tríade, ambos ambientados no contexto da Revolução Francesa. O autor faz uma análise minuciosa sobre os elementos contidos nos jogos, tais como manuais, menus e teclas de navegação. E, a partir disso, explica as diferenças entre os jogos educacionais e comerciais, refletindo sobre os motivos da preferência dos jovens pelos jogos comerciais a despeito dos que possuem fins educacionais.

Em 2016, Laura Bossle Caríssimi propôs o jogo Arquivo 7.0, utilizando-se da leitura e interpretação de documentos ficcionais referentes ao período da Ditadura Civil-Militar, na década de 1970. André Luís da Costa Corrêa (2017) refletiu a agência histórica, contextos, estruturas e conjunturas a partir da modalidade RPG, associando o jogo como estímulo para a iniciação científica. Mateus Pinho Bernardes (2017) criou um jogo de tabuleiro sobre a greve geral de 1917 em São Paulo que funciona através de uma mecânica cooperativa capaz de desenvolver nos alunos empatia histórica e a noção de que a história é um conjunto de ações e escolhas de indivíduos diante das estruturas do tempo.

No ano seguinte Bruno Barros da Silva (2018) defendeu a dissertação Da autobiografia ao jogo: o ensino das relações étnico-raciais a partir das experiências de Mahommah Gardo Baquaqua. O autor detectou estereótipos relacionados ao ser negro e ao continente africano e, a partir disso, viabilizou, através do jogo de tabuleiro autobiográfico, discussões acerca destes estereótipos. Hugo Alexandre 
de Araújo (2018) explorou o conceito de nação, sendo proposto um jogo de cartas como parte do projeto, entendido como alternativa didática para compreender conceitos aos quais os alunos apresentam dificuldades. Renato César Ferreira (2018) pensou o jogo como alternativa lúdica para despertar a relação de pertencimento social e impulsionar a memorização do conteúdo, abordando a história local de Rolândia (PR). Valéria Cristina Moreira (2018) entendeu o jogo como meio alternativo aos materiais tradicionais, criando um jogo de RPG sobre a Guerra do Paraguai, destacando a participação de grupos minoritários geralmente apagados da história. Angelo Tiago Pretto (2018) dedicou-se a compreender como os meios digitais possibilitam prazer aos alunos de periferia, que são economicamente vulneráveis e, portanto, excluídos da vida cultural e política. Nos meios digitais, há a possibilidade de acesso àquilo que não se faz presente materialmente na vida dos estudantes. Lenna Carolina Solé Vernin (2018) criou um "jogo de memórias", visando a positivação de identidades dos moradores do Campo de Santana através da análise patrimonial e memorialística do parque. Helyom Viana Telles (2018) refletiu a partir da aplicação de jogos digitais, tendo como foco a noção de "empatia histórica". Elton Frias Zanoni (2016) procedeu a uma inserção de elementos de jogos em sala de aula para melhorar habilidades cognitivas (especialmente a memória).

Muito recente, no início de 2019, a revista História, Histórias, do programa de pós-graduação em História da Universidade de Brasília, publicou um dossiê com 5 artigos sobre a temática: dois tematizam o jogo Sid Meier's Civilization (FORNACIARI, 2019; SILVA, 2019); dois abordam as possibilidades educativas de dois jogos produzidos no âmbito do PROFHISTORIA (BERNARDES, 2019; CARÍSSIMI; RADUNZ, 2019); e o quinto, de autoria de Rodrigo Cardoso Soares de Araújo (2019), lança reflexões teóricas sobre o uso de jogos no ensino de História e analisa os limites e possibilidades dos jogos "educativos".

A visão panorâmica da produção sobre a temática abordada revela o avanço coletivo da reflexão sobre dois aspectos: as possibilidades didáticas do uso jogos na história escolar e a metodologia para a construção de jogos com fins didáticos. Algumas tendências são perceptíveis. Enquanto jogos de RPG e tabuleiro são os principais artefatos lúdicos criados pelos pesquisadores (dada a possibilidade material do mesmo), há uma abundância de pesquisas que dão enfoque aos jogos 
A pesquisa sobre jogos como recursos didáticos no campo do

Ensino de História no Brasil:

digitais. Em algumas pesquisas, há a criação de videogames; em outras, os produtos comercializados que contêm elementos de História são analisados, sempre com o questionamento da possibilidade de constituir algum aprendizado histórico com eles, e se são de fato alternativas ao ensino tradicional de história. Nesse sentido, o conceito de gamificação é inserido no debate ${ }^{7}$.

\section{A caminhada teórica}

Do ponto de vista teórico, as abordagens teóricas praticadas são múltiplas e variadas. A ampla maioria dos trabalhos tomou como referência para a conceituação de jogo a obra Homo Ludens do historiador medievalista holandês Johan Huizinga (2014) e para as relações entre jogo e educação trabalharam a obra do pesquisador francês Gilles Brougère (2003). Os especialistas em jogos digitais dialogam com Jesper Juul (2019), pesquisador dinamarquês pioneiro dos Game Studies ou Ludologia, e Adam Chapman (2018), dentre outros.

Em especial, a obra de Huizinga (2014), mesmo que não engajada diretamente na reflexão pedagógica, é fartamente utilizada por exemplo na conceituação de jogo e na definição das suas dimensões formativas no campo dos afetos, da cognição e da moral. Para Huizinga, jogar é uma atividade voluntária, livre, desinteressada. Ou melhor, tem um fim em si mesmo. Joga-se para se jogar. E o jogo cria uma esfera temporária de atividade, produz uma evasão da vida real, um intervalo no cotidiano: o "faz de conta" que é capaz de absorver o jogador de maneira intensa. Assim, o jogo impõe uma ordem específica e absoluta pois cria ordem e é ordem (pois cria estabilidade e uma perfeição temporárias no caos da

\footnotetext{
${ }^{7}$ Movimentos recentes de docentes e investigadores indicam a criação de novos espaços atuação e divulgação da produção sobre a temática. Com o objetivo de articular docentes, pesquisadores e pesquisadoras deste recente campo, em 2018, foi criada a Rede de Pesquisadores e Pesquisadoras sobre jogos no ensino de História (REJOGO), que atualmente funciona como uma lista de correio eletrônico que tem servido para o compartilhamento da produção científica sobre o tema, bem como para a divulgação de eventos acadêmicos pertinentes ao objeto de investigação. Espera-se que a rede potencialize as trocas intelectuais assim como organize eventos científicos regulares. Vale ressaltar, ainda, no encontro ocorrido em 2019, na cidade do Recife, a presença do primeiro simpósio temático exclusivo sobre o tema na tradição do Simpósio Nacional da Associação Nacional de História (ANPUH-Brasil) com 20 trabalhos aprovados, dos quais 16 tratam especificamente sobre jogos digitais e jogos de tabuleiro como recursos didáticos e produtores de representações de nossa cultura histórica, metodologia da construção de jogos com fins didático, jogos teatrais, dentre outras possibilidades. Cf. https://www.snh2019. anpuh.org/simposio/view?ID SIMPOSIO=257
} 
vida). Quebrar esta ordem "estraga" o lúdico e quebra a ilusão (de illudere). Ou seja, o jogo ajuda na aprendizagem da concentração, da objetividade do que tem um fim em si mesmo. Para Huizinga, o jogo também traz consigo um elemento ético pois põe à prova as qualidades do jogador: força, tenacidade, habilidade, coragem e sobretudo sua lealdade às regras e à ilusão criada. Nesse sentido, o jogo possui uma funcionalidade semelhante à do discurso pedagógico. Ambos se revelam impulsos na direção da verdade e da justiça pelo compartilhamento do conhecimento e compromisso pela vida.

Também, é a lealdade às regras e à ilusão que permite que o jogo nos coloque suspensos no tempo cronológico, esquecidos de quem nós somos, engajados em sermos outros personagens atuando na ficção lúdica, no "faz de conta". Esquecemos do tempo cronológico e nos colocarmos em estado de abertura. O jogador faz um movimento semelhante ao que é realizado pelo leitor durante a leitura: desce o olhar até o jogo, rende-se à ilusão, despersonaliza-se, simula assumir outros papéis. E quando a partida termina, ele levanta novamente o olhar, renasce outro, interrompendo a ilusão e se recolocando no presente do tempo. Neste sentido, o jogo ensina a imaginar futuros possível pois brinca com o virtual, com o "e se..."

A experiência do jogo, de um modo geral, é também social uma vez que produz vínculos e promove a formação de grupos sociais "com a tendência a rodearem-se em segredo e a sublinharem sua diferença em relação ao mundo por meio de disfarces ou outros meios semelhantes", segundo Huizinga (2014, p. 15). É uma experiência que se vive em paralelo a outras. E mais, o jogo só existe também como relação entre jogadores, como prática.

Segundo Huizinga (2014, p. 15),

Desde a mais tenra infância, o encanto do jogo é reforçado por se fazer dele um segredo. Isto é, para nós, e não para os outros. O que os outros fazem, "lá fora", é coisa de momento não nos importa. Dentro do círculo do jogo, as leis e costumes da vida quotidiana perdem validade. Somos diferentes e fazemos coisas diferentes.

As mesas de jogos produzem amizade. Para Huizinga (2014), não temos como retirar o papel do lúdico na formação de agrupamentos sociais permanentes como clubes, clãs, irmandades, fraternidades, dentre outros. As excepcionalidades do jogo, seu ar de mistério, o clima de tensão, envolve seus parceiros e cimenta a parceria. E jogar na escola é mudar qualitativamente os vínculos entre docentes 
e estudantes no sentido da cooperação, do afeto, do compartilhamento de emoções. Não por acaso vários pesquisadores arrolados anteriormente utilizaram os jogos sob a prerrogativa de que eles possibilitam aos alunos entrar em contato com grupos sociais marginalizados (como mulheres, negros, indígenas, etc) de maneira imersiva. Nesse sentido, projeta-se na ação pedagógica com jogos a capacidade que eles têm de tornarem os jogadores empáticos para com os outros e o impacto de representatividade na construção dos sujeitos, já que pessoas que pertencem a esses grupos marginalizados também jogam.

Dentro deste universo pesquisado, ainda no cenário brasileiro, há trabalhos que expressam um olhar teórico construtivista, assim como outros que dialogam com a perspectiva teórica alemã de Jorn Rüsen (2007). Sem dúvida, dialogando com Vygotsky (1998a, 1998b), o trabalho de Arruda (2009) lançou luzes sobre as aprendizagens possibilitadas pelo acesso a jogos digitais de temática histórica, bem como sobre como os jovens jogadores organizam e refletem sobre as informações históricas articuladas em torno das partidas, estabelecem laços e interagem entre si, criam suas próprias estratégias de aprendizagem visando o uso da história no jogo ou na escola, narram e imaginam o passado e estabelecem uma posição crítica sobre ele.

Outra abordagem teórica constrói diálogos com pensadores como Henri Bergson (2010), Gilles Deleuze (2009) e Jorge Larrosa-Bondiá (2002, 2015). Dialogamos com as investigações inspiradas nesta trilha teórica na certeza de que é possível inclusive repensar os próprios objetivos do ensino de História, tomando o jogo como ponto privilegiado de observação. Nilton Mullet Pereira e Gabriel Torelly (2015), por exemplo, atuam na produção de fundamentos teóricos para o ensino de História através de artefatos lúdicos ao proporem a compreensão do jogar enquanto exercício de imaginação e fabulação. Para os autores, jogar é poder imaginar, fabular como as coisas se passaram. É experimentar a indeterminação da história virtual de desfecho incerto e com a realidade histórica permitindo outros usos do conceito e diferentes possibilidades de escrita da história e de experimentação da densidade de um conceito.

Para além das finalidades iluministas, racionalistas da história escolar, Pereira e Torelly (2015) avançam ao afirmarem que o ensino de História precisa ir além do ensinar a pensar historicamente ou do desenvolvimento da consciência 
histórica. Para além de possibilitar a orientação para a vida prática, deve ensinar uma relação com o passado enquanto abertura visando a expansão da vida. O que significa também (in)corporar à história escolar sentimentos, sensibilidades, matérias essas inseparáveis do jogo. Para os autores, os estudantes precisam se relacionar com o passado sob o modo da abertura: devem se expor ao passado e dele fazer experiência, tomar o passado enquanto espaço-tempo ilimitado, matéria não formada, possibilidade de experiência. O passado como potência aberta à interpretação e fluxo da diferença. Por isso, o brinquedo na sala de aula pode ser uma dádiva formativa, tamanha sua capacidade de mediar relações outras com a temporalidade humana em si: permite flutuar em uma espacialidade ideal, entre passado e o presente! Em outras palavras, o jogo nos leva ao espaço da diferença potencial, ao "e se...", ao território da ficção, da experiência, do nãoconhecimento, do que é possível, ou seja, o mesmo lugar da criação dos conceitos.

Neste sentido, o jogo ensina a imaginar futuros possíveis, pois destaca o jogador dos limites da atualidade, para transporta-lo para uma virtualidade que expande a potência da vida, permitindo-Ihe brincar com o passado e com as narrativas que produzimos a cerca dele. Um exemplo bastante significativo é o "e se", momento no qual nos levamos a perguntar: "e se não tivesse ocorrido assim?" "e se o nazismo não tivesse existido?" "e se pudéssemos pensar um mundo sem ódio, preconceito, privilégios e intolerância?". São questões que inserem em nossa relação com o passado um elemento ético que nos leva a pensar sobre o mundo e sobre nós mesmos. Essa virtualidade em que consiste o ambiente do jogo consiste numa potência que afirma sempre a diferença.

\section{Considerações finais}

Ainda temos desafios a consolidação da investigação pedagógica dos jogos no ensino de História. Mesmo que apressadamente, podemos inferir que a pesquisa em jogos no ensino de História avançou na fundamentação teórico necessária como justificativa para o uso de jogos como recursos.

Apontamos um cuidado: a aula expositiva, a leitura de textos ou resolução de atividades muitas vezes são tratadas como vilãs do ensino, associadas à "chatice" e ao marasmo, considerada necessariamente melhor qualquer proposta 
que se distancie desse modelo de ensino. As faculdades do imaginar, do criar e do analisar novas formas de ensinar e aprender são imperativos para constituir-se um bom ensino de História, mas é também preciso ficar atento: um jogo pode ser também tradicional (no sentido ruim da palavra) e monótono, se ele for pensado apenas como um mero suporte para aquilo que estava na aula expositiva ou nos textos. Processos de didatização não podem matar o jogo.

Se o objetivo pedagógico do jogo é apenas obter o maior número de informações possíveis sobre aquilo que se está estudando, deixando em segundo plano (ou mesmo ignorando) as estéticas criadas pela interação dinâmica com as mecânicas do jogo, imobilizando as ações dos jogadores, estará este jogo sendo inovador? Ele consegue atrair a atenção dos alunos? Ele consegue ser uma experiência?

Percebemos que ainda precisamos avançar sobretudo na investigação sobre os resultados efetivos do uso dos jogos no chão da sala de aula no que diz respeito à relação professor-aluno e demais interações sociais em sala, sobre a eficácia dos recursos lúdicos na promoção das aprendizagens como também a recepção discente das narrativas históricas presentes nos jogos, dentre outras possibilidades.

A investigação das práticas lúdicas também precisa se aproximar das práticas docentes. Jogos de tabuleiro, gincanas, RPG, jogos teatrais, quiz, jogos digitais: o que se joga efetivamente nas nossas salas de aula? Ainda não sabemos, pois ainda não foi encontrado nenhum mapeamento de experiências lúdicas no contexto da história escolar.

E, por fim, também chamamos a atenção para a investigação das implicações morais dos jogos na aula de História: a violência das guerras, da escravidão, dos conflitos sociais, representada nos jogos contribuiria para a sua banalização? É pertinente jogar e se divertir com quaisquer temáticas históricas, mesmo as mais sensíveis e traumáticas?

Ao jogo!

\section{Referências}

ALBUQUERQUE JÚNIOR, Durval Muniz. Por um ensino que deforme: o futuro da prática docente no campo da história. In: ALBUQUERQUE JÚNIOR, Durval Muniz. 
O tecelão dos tempos: novos ensaios de teoria da história. São Paulo: Intermeios, 2019. p. 233 - 243.

ALVES, Lynn Rosalina Gama. Game over: jogos eletrônicos e violência. São Paulo: Futura, 2005.

ALVES, Lynn Rosalina Gama. Jogos, Educação e História: Novas Possibilidades para a Geração C. Plurais Revista Multidisciplinar, v.1, n. 2, 2010.

ALVES, Lynn Rosalina Gama; COUTINHO, I. (org.). Jogos digitais e aprendizagem: fundamentos para uma prática baseada em evidências. Campinas: Papirus, 2016.

ALVES, Lynn Rosalina Gama; TELLES, H. V. Ensino de história e videogame: problematizando a avaliação de jogos baseados em representações do passado. In: ALVES, Lynn Rosalina Gama; TELLES, H. V. (org.). Jogos digitais e aprendizagem: fundamentos para uma prática baseada em evidências. Campinas: Papirus Editora, 2016a. p. 125-146.

ALVES, Lynn Rosalina Gama; TELLES, H. V. Ficção e narrativa: o lugar dos videogames no ensino de História. TECCOGS, São Paulo, v. 11, p. 115-130, 2016b.

ALVES, Lynn Rosalina Gama; TELLES, H. V. Os videogames como narrativas sobre o passado na pós-modernidade. Revista do Programa Avançado de Cultura Contemporânea, Rio de Janeiro, v. 16, p. 1-6, 2017.

ALVES, Lynn Rosalina Gama; MATTA, Alfredo; TELLES, Helyon (Org.) Museus virtuais e jogos digitais: novas linguagens para o estudo da história. Salvador: EDUFBA, 2019.

ANDRADE, Débora El-Jaick. O lúdico e o sério: experiências com jogos no ensino de história. História \& Ensino, Londrina, v. 13, p. 91- 106, set. 2007.

ARAÚJO, Hugo Alexandre de. Múltiplos olhares para a aprendizagem histórica: o conceito de nação através de evidências visuais. 2018. Dissertação (Mestrado Profissional em Ensino de História) - Universidade Federal de Pernambuco, Recife, 2018.

ARAÚJO, Renata Costa Silva. Nunca foi tão divertido descascar batatas: os jogos como possibilidade a ser explorada no ensino de história. História, histórias, Brasília, v. 7, n. 1/3, jan./jun. 2019. Disponível em:

https://periodicos.unb.br/index.php/hh/announcement/view/110. Acesso em: 10 nov. 2019.

ARRUDA, Eucidio Pimenta. Jogos digitais e aprendizagens: o jogo Age of Empires III desenvolve ideias e raciocínios históricos de jovens jogadores?. 2009. Tese (Doutorado) - Universidade Federal de Minas Gerais, 2009.

BERGSON, Henri. Matéria e memória: ensaio sobre a relação do corpo com o espírito. São Paulo: Martins Fontes, 2010. 
BERNARDES, Mateus Pinho. À luta camaradas! a greve geral de 1917. São Paulo: ensino de história e análises de conjuntura através de um jogo de tabuleiro moderno. 2017. Dissertação (Mestrado Profissional em Ensino de História) Universidade Federal de Santa Catarina, Florianópolis, 2017.

BERNARDES, Mateus Pinho. Reflexões sobre o lançar de dados na sala de aula: considerações sobre o desenvolvimento de um jogo de tabuleiro moderno para o ensino de História e suas possibilidades. História, histórias, Brasília, v. 7, n. 1/3, jan./jun. 2019. Disponível em:

https://periodicos.unb.br/index.php/hh/announcement/view/110. Acesso em: 10 nov. 2019.

BRASIL. Parâmetros Curriculares Nacionais: primeiro e segundo ciclos do Ensino. Brasília: MEC, 1998. Disponível em: http://portal.mec.gov.br. Acesso em: 10 nov. 2019.

BROUGÈRE, Gilles. Jogo e educação. Porto Alegre: Editora Artes Médicas, 2003.

CAILLOIS, Roger. Os jogos e os homens: a máscara e a vertigem. Petrópolis: Editora Vozes, 2017.

CARÍSSIMI, Laura Bossle. O jogo como suporte pedagógico e a utilização de documentos no ensino de História. 2016. Dissertação (Mestrado) - Universidade de Caxias do Sul, Caxias do Sul, 2016.

CARÍSSIMI, Laura Bossle; RADUNZ, R. A Ditadura Civil Militar e o ensino de História: o jogo Arquivo 7.0. História, histórias, Brasília, v. 7, n. 1/3, jan./jun. 2019. Disponível em:

https://periodicos.unb.br/index.php/hh/announcement/view/110. Acesso em: 10 nov. 2019.

CERTEAU, Michel de. A escrita da história. Rio de Janeiro: Forense Universitária, 2002.

CHAPMAN, Adam. Digital Games as history: how videogames represent the past and offer access to historical practice. Abingdon: Routledge, 2018.

COMUNIDADES VIRTUAIS. Jogos digitais. Cabula: Comunidades Virtuais, 2019. Disponível em: http://comunidadesvirtuais.pro.br/cv/. Acesso em: 10 nov. 2019.

COSTA, Carlos E. S. RPG e ensino de história: uma articulação potente para a produção da narrativa histórica escolar. 2016. Dissertação (Mestrado Profissional em Ensino de História) - Universidade Federal do Rio de Janeiro, Rio de Janeiro, 2016.

COSTA, M. A. F. Ensino de história e games: dimensões práticas em sala de aula. Curitiba: Apriss, 2017.

CORRÊA, André Luís da Costa. Rolando dados, criando histórias, aprendendo história: o uso do RPG como instrumento de iniciação científica no Ensino de 
História. 2017. Dissertação (Mestrado Profissional em Ensino de História) Universidade Federal do Rio Grande do Sul, Porto Alegre, 2017.

CUNHA, Bruno Ornelas. Jogo urbano: história local no ensino de história. 2016. Dissertação (Mestrado Profissional em Ensino de História) - Universidade Federal Fluminense, Rio de Janeiro, 2016.

DELEUZE, Gilles. Diferença e repetição. Rio de Janeiro: Graal, 2009.

FERMIANO, Maria A. Belintane. O Jogo como um instrumento de trabalho no ensino de História?. Revista História Hoje, São Paulo, v. 3, n. 7, jul. 2005. Disponível em: www.anpuh.uepg.br/historiahoje/voI3n7/ maria.htm. Acesso em 10 nov. 2019.

FERREIRA, Renato César. Brincando com o perfil histórico de Rolândia: o lúdico entre o patrimônio histórico oficial e patrimônio histórico afetivo. 2018. Dissertação (Mestrado Profissional em Ensino de História) - UNESPAR, Campo Mourão, 2018.

FERREIRA, Norma Sandra de Almeida. As pesquisas denominadas "Estado da arte". Educação \& Sociedade, Campinas, v. 23, n. 79, ago. 2002.

FORNACIARI, Marco de Almeida. Progredir ou perecer: modernidade, aceleração da história e etnocentrismo em Sid Meier's Civilization. História, histórias, Brasília, v. 7, n. 1/3, jan./jun. 2019. Disponível em: https://periodicos.unb.br/index.php/hh/announcement/view/110. Acesso em: 10 nov. 2019.

FORTUNA, Tânia Ramos. Jogo em aula: recurso permite repensar as relações de ensino-aprendizagem. Revista do Professor, Rio Pardo, v. 19, n. 75, p. 15-19, 2003.

FORTUNA, Tânia Ramos. A formação lúdica docente e a universidade: contribuições da Ludobiografia e da Hermenêutica Filosófica. 2011. Tese (Doutorado) - Universidade Federal do Rio Grande do Sul, Porto Alegre, 2011a.

FORTUNA, Tânia Ramos. Sala de aula é lugar de brincar? a importância do lúdico no planejamento. In: DALLA ZEN, Maria Isabel H.; XAVIER, Maria Luiza M. (org.). Planejamento em destaque: análises menos convencionais. 4. ed. Porto Alegre: Editora Mediação, 2011b. p. 117-132.

FORTUNA, Tânia Ramos. Brincar é aprender. In: GIACOMONI, Marcello Paniz;

PEREIRA, Nilton Mullet (org.). Jogos e ensino de história. Porto Alegre: Evangraf, 2013. p. $63-97$.

FORTUNA, Tânia Ramos; HORN, C. I.; FORNARI, F. V.; SILVA, J. S.; SANTOS, V. L. B.; POTHIN, J. Pedagogia do Brincar. Porto Alegre: Mediação, 2012. 
GIACOMONI. Marcello Paniz; PEREIRA, Nilton Mullet. Jogos e ensino de história. Porto Alegre: Evangraf, 2013.

GIACOMONI, Marcello Paniz. Ensino de história e jogos de tabuleiro: o centralizador. In: SIMPÓSIO NACIONAL DE HISTORIA, 27., 2013, Natal. Anais [...]. Natal: Anpuh, 2013b. Disponível em:

http://www.snh2013.anpuh.org/conteudo/view?ID_CONTEUDO=1291. Acesso em: 10 nov. 2019.

GOMES, José Anderson Costa. Jogos digitais no ensino de história: uma análise do jogo Tríade - igualdade, liberdade e fraternidade. 2019. Dissertação (Mestrado) - Universidade do Estado do Rio Grande do Norte, Natal, 2019.

HUIZINGA, Johan. Homo ludens: o jogo como elemento da cultura. São Paulo: Perspectiva, 2014.

JOGOS DIGITAIS PARA ENSINAR HISTÓRIA. Home. [S. I.]: Daiana Cecatto, 2019. Disponível em: https://www.jogosdehistoria.net/. Acesso em: 10 nov. 2019.

JUUL, Jesper. Half-real: videogames entre regras reais e mundos ficcionais. São Paulo: Blucher, 2019.

KISHIMOTO, Tizuko M.O jogo e a educação infantil. Pro-Posições, Campinas, v. 6 n. 2, p. 46-63, jul.1995. Disponível em:

https://periodicos.sbu.unicamp.br/ojs/index.php/proposic/article/view/8644269. Acesso em: 10 nov. 2019.

KISHIMOTO, Tizuko M. Jogo e educação infantil. São Paulo: Cengage Leaning, 2009.

KISHIMOTO, Tizuko M. (org.). Jogo, brinquedo, brincadeira e a educação. São Paulo: Cortez, 1996.

KISHIMOTO, Tizuko M.; SANTOS, M. W. (org.). Jogos e brincadeiras tempos, espaços e diversidade: pesquisas em educação. São Paulo: Cortez Editora, 2016.

LARROSA-BONDÍA, Jorge. Pedagogia profana. Tradução de Alfredo Veiga-Neto. São Paulo: Autêntica, 2015.

LARROSA-BONDÍA, Jorge. Notas sobre a experiência e o saber de experiência. Revista Brasileira de Educação, Rio de Janeiro, n.19, p. 20-28,2002.

LOPES, Lucas R. S. Jogando com a crítica histórica: as novas tecnologias e o desenvolvimento de os revoltosos. 2016. Dissertação (Mestrado Profissional em Ensino de História), UDESC, Florianópolis, 2016.

LOPES, A. P. L.; BERLIM, Renato. Dados e cartas na escola: o potencial pedagógico dos jogos não-eletrônicos. In: SIMPÓSIO BRASILEIRO DE JOGOS E 
ENTRETENIMENTO DIGITAL (SBGAMES), 11., 2012, Brasília. Anais [...]. Brasília: [s. n.], 2012. p. 172-175. Disponível em:

http://sbgames.org/sbgames2012/proceedings/papers/cultura/C_S12.pdf .

Acesso em: 10 nov. 2019.

LOPES, A. P. L. Lições em jogo. Revista de História da Biblioteca Nacional, Brasília, n.72, p. 76-79, 2011.

MACEDO, Társio Roberto Lopes. Games com narrativa histórica como mediação de experiências formativas em ensino de história: uma pesquisa com o jogo "Game of Thrones - RPG. 2013. Dissertação (Mestraddo) - Universidade do Estado da Bahia, Salvador, 2013.

MAIA, Márcia Souza S. Parque Indígena do Xingu: um jogo para a lei 11.645/2008. 2016. Dissertação (Mestrado Profissional em Ensino de História) Pontifícia Universidade Católica do Rio de Janeiro, Rio de Janeiro, 2016.

MOREIRA, Valéria C. Ensino de história e RPG como ferramenta nos estudos regionais: possibilidades em "a retirada da laguna" de Alfredo d' Escragnolle Taunay. 2018. Dissertação (Mestrado Profissional em Ensino de História) Universidade Estadual do Matogrosso do Sul, Amambai, 2018.

PEIXOTO, Arthur D. Jogar com a história: concepções de tempo e História em dois jogos digitais baseados na temática da Revolução Francesa. 2016. Dissertação (Mestrado Profissional em Ensino de História) - Universidade do Federal do Rio Grande do Sul, Porto Alegre, 2016. Disponível em: https://educapes.capes.gov.br/handle/capes/173442. Acesso em: 10 nov. 2019.

PEREIRA, Nilton Mullet et al. As viagens do Tambor. Porto Alegre: UFRGS, 2019. 1Jogo de tabuleiro.

PEREIRA, Nilton M.; TORELLY, Gabriel Fraga. O Jogo e o conceito: sobre o ato criativo na aula de História. Opsis, Catalão, v. 15, p. 88-100, 2015. Disponível em: https://www.revistas.ufg.br/Opsis/article/view/34727. Acesso em: 10 nov. 2019.

PEREIRA, Nilton Mullet; GIACOMONI, M. P. Flertando com o caos: os jogos no ensino de história. In: PEREIRA, N. M.; GIACOMONI, M. P. (org.). Jogos e ensino de história. Porto Alegre: Evangraf, 2013. p. 9-23.

PRETTO, Angelo Tiago. Games na sala de aula: formação discente e docente. 2018. Dissertação (Mestrado Profissional em Ensino de História) - Universidade Federal de Santa Maria, Santa Maria, 2018.

RITTER, Tatiane de Souza. Jogo analógico para o ensino de história agrária em uma escola do campo. 2016. Dissertação (Mestrado Profissional em Ensino de História) - Universidade Federal de Santa Maria, Santa Maria, 2016.

RÜSEN, Jörn. História viva: teoria da história: formas e funções do conhecimento histórico. Brasília: UnB, 2007. 
SANTOS, Bergston Luan. Interpretando mundos: jogos digitais e aprendizagem histórica. 2014. Dissertação (Mestrado) - Universidade Federal de Uberlândia, Uberlândia, 2014.

SILVA, Alex Alvarez. Aprendizagem histórica e simulações: desafios do tempo histórico em jogos eletrônicos. In: ENCONTRO ESTADUAL DE HISTÓRIA ANPUH BA, 8., 2016, Feira de Santana. Anais [...]. Feira de Santana: Anpuh, 2016. Disponível em:

http://www.encontro2016.bahia.anpuh.org/simposio/anaiscomplementares.

Acesso em: 10 nov. 2019.

SILVA, Alex Alvarez. Simulações históricas e aprendizagem de conceitos: construindo ferramentas de análise da aprendizagem histórica em jogos eletrônicos. Anais eletrônicos do XII SJEEC Jogos Eletrônicos - Educação Comunicação, Salvador, 2017a. Disponível em:

http://revistas.uneb.br/index.php/sjec. Acesso em: 10 nov. 2019.

SILVA, Alex Alvarez. Aprendizagem histórica e jogos eletrônicos: a consciência histórica entre o conhecimento e a simulação. In: SIMPÓSIO NACIONAL DE HISTÓRIA; SIMPÓSIO NACIONAL DE HISTÓRIA - CONTRA OS PRECONCEITOS: HISTÓRIA E DEMOCRACIA, 29., 2017, Brasília. Anais [...]. Brasília: Anpuh, 2017b. Disponível em: https://www.snh2017.anpuh.org/site/anais. Acesso em: 10 nov. 2019.

SILVA, Alex Alvarez. Narrativas históricas em jogos eletrônicos: a ficcionalização da história em Sid Meier's Civilization. In: ENCONTRO NACIONAL PERSPECTIVAS DO ENSINO DE HISTÓRIA, 10.,; JORNADA DO GT DE ENSINO DE HISTÓRIA E EDUCAÇÃO DA ANPUH/RS, 23., 2018, Porto Alegre. Anais [...]. Porto Alegre: Anpuh, 2018. Disponível em: https://www.ufrgs.br/lhiste/anais-perspectivas-doensino-de-historia/. Acesso em: 10 nov. 2019.

SILVA, Alex Alvarez. Simulação do tempo histórico em jogos eletrônicos. História, histórias, Brasília, v. 7, n. 1/3, jan./jun. 2019. Disponível em: https://periodicos.unb.br/index.php/hh/announcement/view/110. Acesso em: 10nov. 2019.

SILVA, Bruno B. Da autobiografia ao jogo: o ensino das relações étnico-raciais a partir das experiências de Mahommah Gardo Baquaqua. 2018. Dissertação (Mestrado Profissional em Ensino de História) - Universidade Federal de Pernambuco, Recife, 2018.

SILVA, Cláudio Rodrigues V. Alea jacta est: a prática docente do professor de história que faz uso do Roleplaying game na sala de aula. 2016. Dissertação (Mestrado) - Universidade Federal de Pernambuco, Recife, 2016.

SILVA, C.R.V.; SILVA, L. V. O roleplaying game e a história ensinada: possibilidades legais no uso do RPG na sala de aula. In: ENCONTRO DE PESQUISA EDUCACIONAL EM PERNAMBUCO, 5.; . EPEPE - EDUCAÇÃO E DESENVOLVIMENTO NA PERSPECTIVA DO DIREITO À EDUCAÇÃO, 5., 2014, 
Garanhuns. Anais [...]. Garanhuns: Fundaj, 2014. Disponível em: https://www.fundaj.gov.br/images/stories/epepe/V EPEPE/EIXO 3/ClaudioRodri goVasconcelos-CO03.pdf . Acesso em: 10nov. 2019.

SILVA, Lucas Victor; SILVA, Cláudio Rodrigo Vasconcelos. Sobre o uso de jogos de tabuleiro no ensino de história: apontamentos sobre possibilidades educativas. In: FERREIRA, Carlos; MOLINA, Ana (org.). Textos e contextos: caminhos do ensino de história. Curitiba: CRV, 2016. p. 479-492.

SILVA, Lucas Victor. Jogos de tabuleiro no ensino de história da África: possibilidades e limites pedagógicos da obra Terras do Sol: entre tambores e lanças. In: ENCONTRO NACIONAL DE PESQUISADORES DO ENSINO DE HISTÓRIA, 11., 2017, Rio de Janeiro. Anais [...]. Rio de Janeiro: UFRJ, 2017. v. 1. p. 152-158. Disponível em: https://xienpeh.ufrj.br/wp-content/uploads/anais xi enpeh final.pdf. Acesso em: 10 nov. 2019.

SILVA, Lucas Victor; FERREIRA, K. A.; SILVA, C. A. Você conhece as mulheres do Brasil? proposta de recurso didático lúdico para o ensino de história. Educação Básica Revista, Belo Horizonte, v. 3, p. 141-152, 2017. Disponivel em: http://www.laplageemrevista.ufscar.br/index.php/REB/article/view/311. Acesso em: 10 nov. 2019

SOARES, Kauan P. Jovens e games: a construção do conhecimento em história no ensino fundamental II com os jogos "Call of Duty". 2018. Dissertação (Mestrado) - Universidade Estácio de Sá, São Paulo, 2018.

TELLES, Helyom Viana. Empatia histórica e jogos digitais: uma proposta para o ensino de História. 2018. Dissertação (Mestrado Profissional em Ensino de História) - Universidade Estadual da Bahia, Salvador, 2018. UFRGS - UNIVERSIDADE FEDERAL RIO GRANDE DO SUL. Quem quer brincar?.Porto Alegre: FACED: UFRGS, 2020. Disponível em: https://www.ufrgs.br/quemquerbrincar/. Acesso em: 4 jun. 2020.

VERNIN, Lena Carolina S. S. Campo de histórias e a batalha pela memória: usos possíveis do Campo de Santana na prática da educação patrimonial. 2018. Dissertação (Mestrado Profissional em Ensino de História) - Universidade Federal do Rio de Janeiro, 2018.

VIAL, Jean. Jogo e educação: as ludotecas. Petrópolis: Vozes, 2015.

VYGOTSKY, Lev Semenovich. A formação social da mente. São Paulo: Martins Fontes, 1998a.

VYGOTSKY, Lev Semenovich. Linguagem, desenvolvimento e aprendizagens. São Paulo: Ícone-EDUSP, 1998b.

ZANONI, Elton Frias. Gamificação, aprendizagem e ensino de história: construção de estratégias didáticas com ferramentas online. 2016. Dissertação (Mestrado Profissional em Ensino de História) - Universidade do Estado de Santa Catarina, 
Florianópolis, 2016. Disponível em:

https://educapes.capes.gov.br/bitstream/capes/173504/1/dissertacao elton fria s zanoni mestradohistoria.pdf. Acesso em: 10nov. 2018.

Recebido em 18 de Dezembro de 2019. Aprovado em 02 de Junho de 2020. 